\title{
Ergonomics and the Musculoskeletal Disorders in the Work of Nurses
}

\author{
Luboslav Dulina ${ }^{1, *}$, Ivana Cechova ${ }^{1}$, Martin Krajcovic ${ }^{1}$ and Martin Gaso ${ }^{1}$ \\ 'University of Zilina, Faculty of Mechanical Engineering, Department of Industrial Engineering, Univerzitna 8215/1, 01026 Zilina, Slovak Republic
}

\begin{abstract}
Ergonomics in healthcare industry is still in its early stages. The role of healthcare personnel is to take care of population's health. This is why it is very important to care about healthcare personnel. First, this article is a presentation of a survey conducted in Slovakia. The survey focused on nurses working in inpatient departments. Therefore, the main objective was to verify the physical nursing workload and determine the most frequent musculoskeletal disorders of nurses. The survey was conducted by using the Nordic Questionnaire. The results of the survey confirm the most serious difficulties for nurses with a musculoskeletal apparatus. Moreover, the results also show pain-related dependence in one body part of a nursing professional depending on his or her profile. The second part of the article shows model situations that may occur in nursing work and the physical loading they impose on health of nursing professionals.
\end{abstract}

Keywords: ergonomics, nurse, physical loading, analysis, Tecnomatix Jack.

\section{Introduction}

The task of ergonomics is to make day-to-day work more human for one person. It should be a beneficial consequence of reducing the workload for a human. Healthcare industry is a specific union from an ergonomic point of view. Ergonomics in a healthcare industry is still in its very early stages. The role of healthcare personnel is to take care of population's health. Healthcare workers are constantly in contact with their patient and this contact often involves real physical interaction [1, 2]. Several types of healthcare workers work in the healthcare industry. The most frequent occupation is a nurse [3].

There are more than 30,000 nurses working in Slovakia, and only 2 percent represents males. Up to one third of nurses are over 50 years old [3]. People in this age group begin to lose functional and working abilities, including physical strength.

Nurses are influenced by mental and physical workload [4]. Therefore, it is difficult to tell which component of the loading is more dangerous for them. The physical loading is very difficult to measure. Also, it is more difficult to eliminate it in the work of a nurse. Nurses are exposed to difficult live situations of patients and their family members every day. Due to this reason, the research is also focused on physical loading.

Nurses have to handle patients on a daily basis. Average weight of a patient is 70 $\mathrm{kg}$. This is several times more than the weight limit for handling loading with both hands for women and men resulting from the legislation of the Slovak Republic [5]. Nurses make non-physiological work postures during their work shift. They work in a posture bending forward, with hands away from their body. High weight of a patient and non-physiological work postures may pose a health risk to nurses. 
The question is - how serious is this risk? It may be verified by the analysis of current situation focused on problems with musculoskeletal system of nurses. The occurrence of musculoskeletal system and its problems may confirm or disprove possible health risks when working as a nurse $[6,7]$.

\section{Experimental Section}

This part of the article introduces methods, which were used to support the survey. First phase of the survey, which was carried out by means of the Nordic Questionnaire, analyses the current state of nurses in Slovakia. The second phase introduced various working position models of nurses in the Tecnomatix Jack software. This phase was linked to problems identified with nurses and musculoskeletal system. This was carried out to find out negative physical factors at work and the impact on their health.

\subsection{Analysis of current status}

This survey was carried out to examine the difficulties of nurses with the musculoskeletal apparatus. Using the Nordic Questionnaire (NQ) helped analyses the current situation in Slovakia. The questionnaire is anonymous, designed to provide information about the occurrence of workrelated difficulties.

Questionnaire was retrieved and processed by The University of lowa, Institute of Preventive and Clinical Medicine in Bratislava. For the analysis of the current status, this questionnaire was modified for nurses. The questionnaire has three basic parts: general information, subjective assessment of difficulties with musculoskeletal system, and subjective assessment of a nurse's reaction to specific situations. The sample of modified Nordic Questionnaire is shown in Fig. 1.

The second part of the questionnaire is important for checking the difficulties with the musculoskeletal system. In this part of the questionnaire, the nurses marked body parts where they felt pain during the last 12 months. They also indicated whether one should visit a doctor or physiotherapist when experiencing this pain. Based on completed questionnaires, current status has been found. The Current status is further analyses and individual ergonomic analyses are carried out.

\subsection{Tecnomatix Jack Software Solution}

Tecnomatix is the Product Board of Siemens PLM Software including several soft-ware tools for various production areas that could be mutually interlinked. Tecnomatix tools enable industrial companies to use the concept of digital factory in practice, plan and project production, design, verify and optimise processes and production sources in a digital environment $[8,9]$.

Tecnomatix Jack module is designed for detailed workplace projection from the ergonomic point of view. Workplace arrangement could be designed,

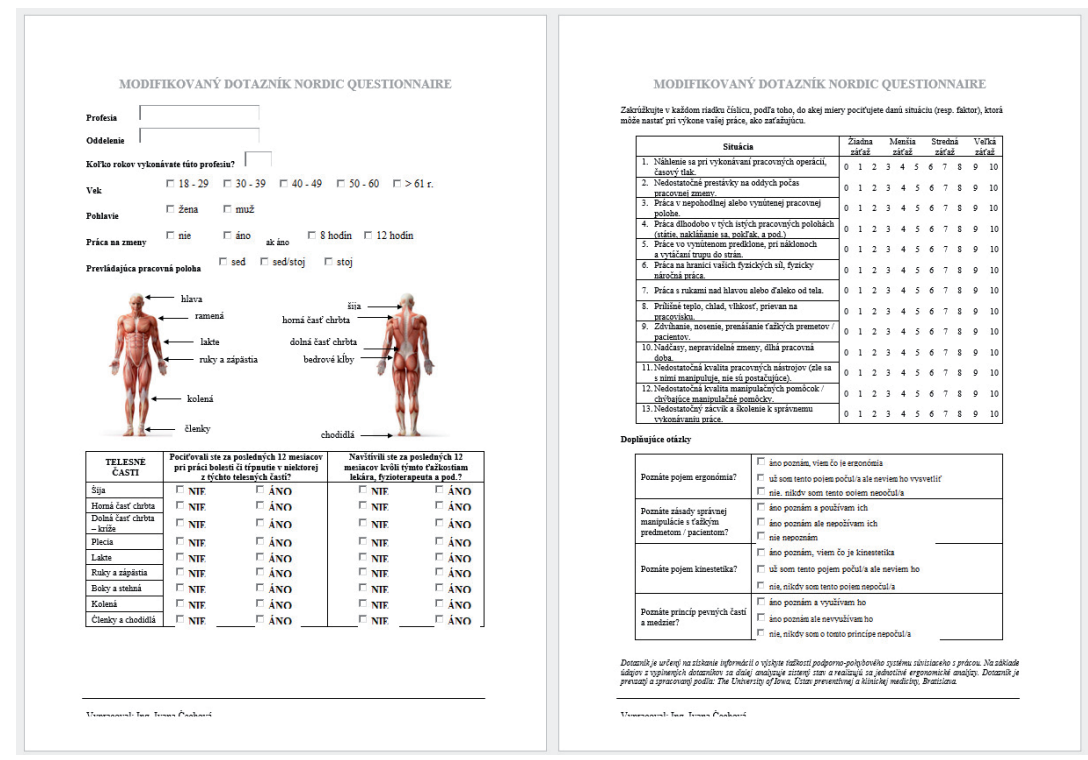

Fig. 1: The modified Nordic Questionnaire sample. [21], [Authors] 
and also exact human model could be inserted anthropometrically and biochemically in this module. This human model needs to be set in detail regarding working position and anthropometrics. The module offers generation of achieved zones, collision detection, opera-tor's field of vision evaluation, etc. Dynamic simulation is also possible apart from static working position modelling. It is also possible to link this module with advanced technologies, such as MoCap (Motion Capture) or Kinect that enables to shorten time of simulation production and make its parameters more precise $[10,11]$. Based on created static model or simulation it is possible to use a number of most-widely used ergonomic analyses. Manual handling limit analyses for evaluation (NIOSH), working position evaluation (OWAS), repetitive work of upper limbs (RULA) and also analysis for evaluation of low back loading on intervertebral disc L4/L5 - Lower Back Analysis (LBA) belong to this group.

To verify the impact of loading caused by nonphysiological working position with manual manipulation - LBA analysis was used. LBA is used to evaluate back loading and muscle tension with patient handling. Evaluation shows strength, pressing the intervertebral disc L4/L5, moments applied in axes and muscle tension. Furthermore, evaluation graphically displays back muscles and their loading depending on the spinal cord position. Therefore, the graph is the result of evaluation revealing the strength pressing on intervertebral disc L4/L5 shown in N. Graph columns are indicated by a colour, depending how risky the strength for low back is. Colours in Table 1 indicate final analysis evaluation LBA.

Table 1: Risk assessment by LBA. [4]

\begin{tabular}{|l|l|} 
& $\begin{array}{l}\text { Nominal risk of low back injury for most } \\
\text { healthy workers. }\end{array}$ \\
\hline & $\begin{array}{l}\text { Increasing risk of low back injury for some } \\
\text { workers, it is recommended this job is be } \\
\text { modified to reduce low back compression } \\
\text { forces. }\end{array}$ \\
\hline $\begin{array}{l}\text { Increased risk of low back injury for most } \\
\text { workers, this job should be re-engineered } \\
\text { immediately to reduce the risk of low back } \\
\text { injury. }\end{array}$
\end{tabular}

\section{Results and Discussion}

The focus of the survey was on nurses working in bed care units, where a greater physical loading is expected. More than 750 respondents were involved in the survey in total. When incomplete responses were filtered, it was revealed they did not refer to nurses (technician, sanitary worker) or to nurses working in ambulance; the total number of respondents was adjusted to 468. These respondents were from 15 different departments of hospitals and from homes of social services.

In the statistical sample, 466 women and 2 men of all age categories were evaluated. The number of years in the profession ranged from 3 months to 49 years. $78 \%$ of the nurses (365 persons) determined the position of alternating sitting and standing as a predominant working position. $18 \%$ of the nurses (83 persons) determined the pre-vailing working position to be standing. Less than $1 \%$ (6 persons) determined the prevailing position to be sitting. The other $3 \%$ of nurses did not comment on this issue.

3.1. Subjective assessment of difficulties with the musculoskeletal system

In the questionnaire, the nurses marked those body parts where they felt pain in the past 12 months. They also indicated whether they visited a doctor or physiotherapist due to this pain. Results for the statistical sample of nurses are shown in Fig. 2.

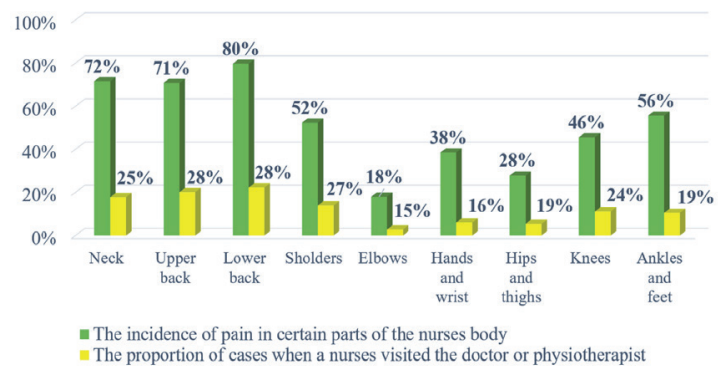

Fig. 2: The incidence of difficulties in body parts of the statistical sample of nurses. [Authors]

The lower back pain was identified as the biggest problem for nurses. Up to $80 \%$ of nurses had a lower back pain during their work. Only $28 \%$ of the nurses visited a doctor or physiotherapist due to this problem. Nurses also experience a pain in their neck and upper back. Similarly, to the lower back, only $25 \%$ respectively $28 \%$ of nurses visited 
a physician or physiotherapist due to their pain. More than $50 \%$ of nurses also feel pain in the shoulders, ankles and feet. In general, it is not possible to say that some of the departments exhibit the greatest or the smallest occurrence of difficulties in the musculoskeletal system. Nurses feel different loading on individual parts of their bodies in different departments.

One of the characteristics of the nurse's profile is the number of years during which she performs her profession. The assumption is that the longer the nurse performs his / her profession, the greater the risk of musculoskeletal system damage and the occurrence of pain. This assumption is made on the basis the nursing work is considered physically demanding. Dependence of the pain occurrence in individual body parts of nurses from the number of years in profession is shown in Fig. 3.

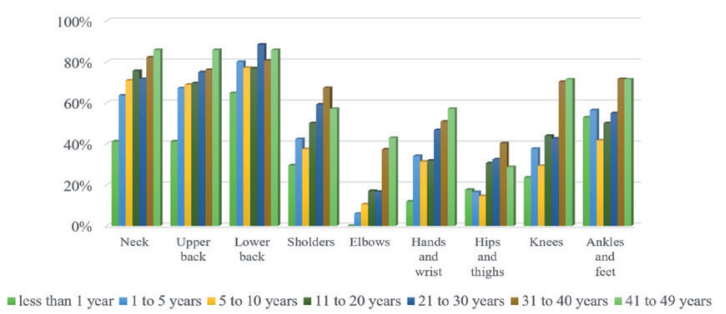

Fig. 3: The incidence of difficulties in body parts of the statistical sample of nurses in dependence on the number of years in their profession. [Authors]

It has been confirmed that the number of years in the profession directly affects the incidence of pain in individual body parts of nurses. Fig. 2 shows a relatively large increase in pain among nurses working less than 1 year and nurses working for 1 to 5 years. This data confirms the fact job of a nurse is physically demanding.

The statistical sample of nurses was also divided into five age groups. The assumption is that with increasing age, the health condition of nurses gets worse. Aging means a decline in functions. It does not begin in old age but in early adulthood. The best physical condition of a person is between 20 to 29 years of life. Once this age is reached, the muscle mass and strength gradually decrease. In connection with this, it is possible to predict an increase in disorders of the individual body parts. Dependence of the occurrence of pain in individual body parts of nurses from their age is shown in Fig.4.

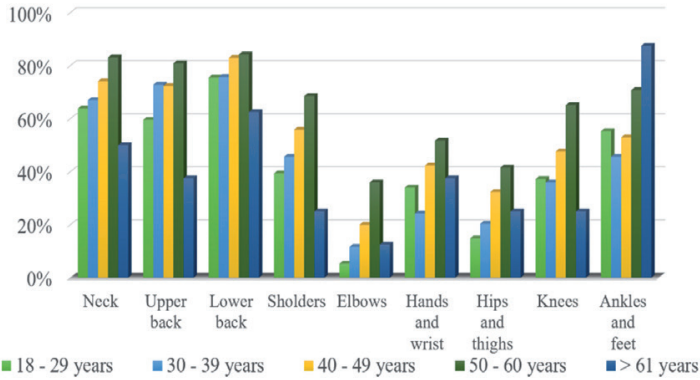

Fig. 4: The incidence of difficulties in body parts of the statistical sample of nurses in dependence on the number of years in their profession. [Authors]

Generally, it has been confirmed, that with the increasing age of nurses the problems with the musculoskeletal system also increase. There is a slight decrease in the age group $>61$ years. This may be due to the fact this age category is a small statistical sample of nurses.

The purpose of the study was to find out whether the work shift affected the incidence of pain in individual body parts. It can be concluded there is no dependence between shift work and the occurrence of problems with the musculoskeletal system. However, the highest percentage may be observed in most body parts of nurses' working irregularly.

Nurses should also indicate their prevailing working posture. They could mark sit-ting, standing or alternating sitting and standing. The assumption reveals the most favourable posture is the alternating sitting and standing posture for the musculoskeletal system. In this case, the lower part of the body is not statically burdened in the long term, which is considered to be favourable for the musculoskeletal system. It is expected that the least frequent problems with the musculoskeletal system will be in the alternating sitting and standing posture. The assumption was not confirmed. It cannot even be said there is a direct connection between the particular prevailing working posture and the incidence of pain in the individual body parts of nurses.

Musculoskeletal system problems stated by nurses, result from the influenced physical burden. Such physical burden is mainly caused by a work in non-physiological working positions together with the manual handling and weight of a patient. Software solution Tecnomatix Jack was used to prove 

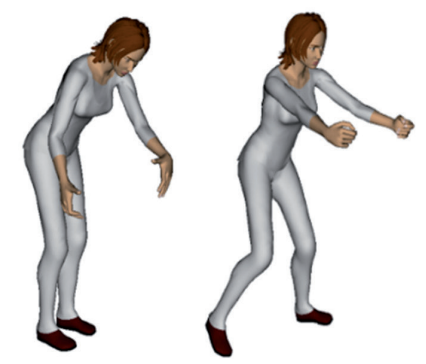

Fig. 5: Working posture in a nursing work. [Authors]

the impact on nurses' health of these 2 factors.

\subsection{Loading impact verification in Tecnomatix Jack}

In order to verify loading influencing patient handling, working positions a nurse can experience during shift work were modelled, together with the added loading causing patient handling. Some of the positions are shown in Fig. 5.

Due to this reason it is not possible to present results for all model positions. Only one was chosen as a representative example. Position that is very common during nurse's work is a patient positioning in bed. Specification of the working position: a nurse is in a non-physiological forward bend position, with her hands far from her body, handling patient's weight. Therefore, there is a synergy of two significant factors causing physical loading and these are non-physiological working position and patient handling. This position modelled in Tecnomatix Jack can be seen in Fig. 6.
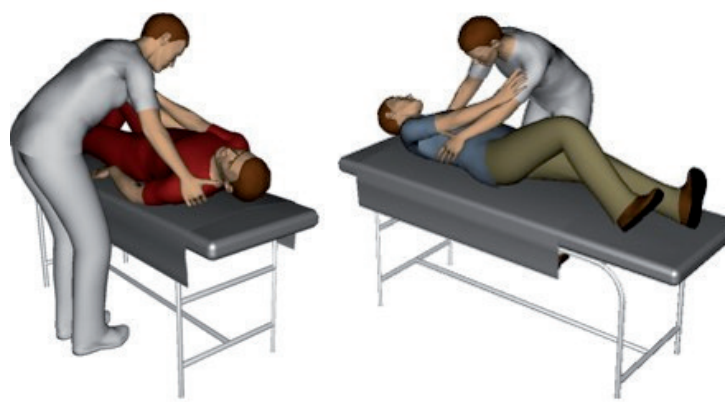

Fig. 6: Patient positioning modelled in Tecnomatix Jack. [Authors]

A model example was used to verify the impact of physical factors on nurse's health. The weight of an average patient was set to $70 \mathrm{~kg}$. In order to make a nurse model, a female model (Jill) and a male model (Jack) were used. 3 percentiles 1, 50 and 99 were used for each model (as the standard in practice). However, there is a speculation about the patient's weight, as the nurse does not usually
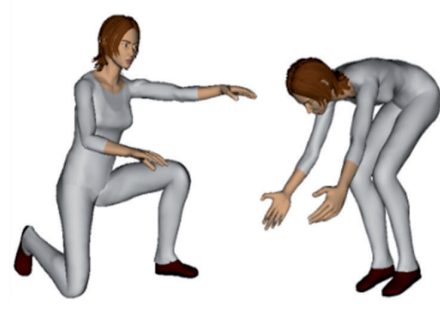

handle $100 \%$ of patient's weight. That is why the patient's weight was adapted. Consequently, loading on intervertebral disc L4/L5, experiencing the largest loading when handling a heavy object was verified through the LBA analysis. The results of a model example are shown in the following tables.

For a female nurse model, there is an existence of health threat caused by physical loading due to a synergy of non-physiological working position and handling a patient. The results show that even with handling weight of $20 \mathrm{~kg}$ (percentile 99), 30 $\mathrm{kg}$ (percentile 50) or $40 \mathrm{~kg}$ (percentile 1) there is an increasing risk of low back damage. Therefore, work should be adapted in a way a pressure on low back would be reduced.

For a model of male nurse there is also existence of health threat due to physical loading caused by synergy of non-physiological working position and handling a patient. Results for men indicate that manipulated weight of $10 \mathrm{~kg}$ (for percentile 99), $20 \mathrm{~kg}$ (for percentile 50) or $30 \mathrm{~kg}$ (for percentile 1) there is an increasing risk of low back damage and work should be adapted in a way there would be lower pressure on low back. It is interesting to see that even though a man might have a better physical presumption for a physical work and higher percentage of physical strength, the model example shows the load on intervertebral disc $L 4 / L 5$ is for same values of loading identical in case of a male nurse.

\section{Conclusions}

To sum it all up, application of a simulation tool Tecnomatix Jack is very significant for ergonomics field in the healthcare industry. Based on results gathered by means of the Nordic Questionnaire (NQ) it is possible to find and verify individual critical working positions and activities and look for dependencies between subjective respondent result of $\mathrm{NQ}$ evaluation and model working 
Table 2: Positioning of a patient, nurse - woman, percentile 1. [Authors]

\begin{tabular}{|l|l|l|l|l|l|l|l|l|l|l|l|}
\hline & \multicolumn{3}{c}{ Sex } & \multicolumn{3}{c}{ Weight [kg] } & \multicolumn{3}{c|}{ Height [cm] } \\
The first case: Percentile 1 & \multicolumn{3}{c}{ Female } & \multicolumn{3}{c}{45} & \multicolumn{3}{c|}{148} & \\
\hline patient weight [\%] & 100 & 90 & 80 & 70 & 6 & 50 & 40 & 30 & 20 & 10 \\
\hline patient weight[kg] & 70 & 63 & 56 & 49 & 42 & 35 & 28 & 21 & 14 & 7 \\
\hline weight on each hand [kg] & 35.0 & 31.5 & 28.0 & 24.5 & 21.0 & 17.5 & 14.0 & 10.5 & 7.0 & 3.5 \\
\hline force on L4/L5 [N] & 7992 & 7231 & 6464 & 5783 & 5182 & 4411 & 3712 & 3020 & 2354 & 1647 \\
\hline
\end{tabular}

Table 3: Positioning of a patient, nurse - woman, percentile 50. [Authors]

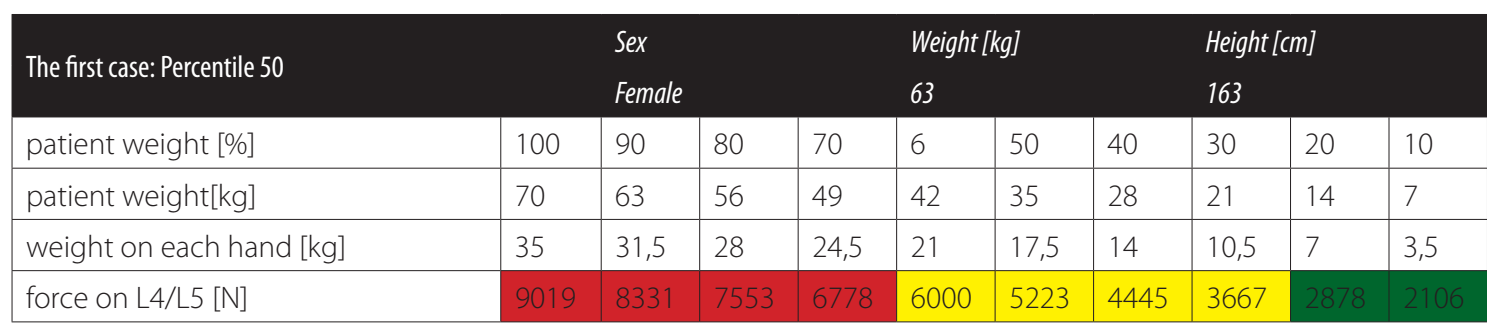

Table 4: Positioning of a patient, nurse - man, percentile 99. [Authors]

\begin{tabular}{|c|c|c|c|c|c|c|c|c|c|c|}
\hline \multicolumn{2}{|l|}{ The first case: Percentile 99} & \multicolumn{3}{|c|}{$\begin{array}{l}\text { Sex } \\
\text { Female }\end{array}$} & \multicolumn{2}{|c|}{$\begin{array}{l}\text { Weight [kg] } \\
85\end{array}$} & \multicolumn{3}{|c|}{$\begin{array}{l}\text { Height [cm] } \\
178\end{array}$} & \\
\hline patient weight [\%] & 100 & 90 & 80 & 70 & 6 & 50 & 40 & 30 & 20 & 10 \\
\hline patient weight[kg] & 70 & 63 & 56 & 49 & 42 & 35 & 28 & 21 & 14 & 7 \\
\hline weight on each hand $[\mathrm{kg}]$ & 35 & 31,5 & 28 & 24,5 & 21 & 17,5 & 14 & 10,5 & 7 & 3,5 \\
\hline force on $L 4 / L 5[N]$ & 10568 & 9694 & 8824 & 7952 & 7085 & 6216 & 5347 & 4478 & 3605 & \\
\hline
\end{tabular}

Table 5: Positioning of a patient, nurse-man, percentile 1. [Authors]

\begin{tabular}{|c|c|c|c|c|c|c|c|c|c|c|}
\hline \multirow{2}{*}{ The first case: Percentile 1} & & \multicolumn{3}{|c|}{ Weight [kg] } & \multicolumn{3}{|c|}{ Height [cm] } \\
\hline & & Male & & & 55 & & & 160 & & \\
\hline patient weight [\%] & 100 & 90 & 80 & 70 & 6 & 50 & 40 & 30 & 20 & 10 \\
\hline patient weight[kg] & 70 & 63 & 56 & 49 & 42 & 35 & 28 & 21 & 14 & 7 \\
\hline weight on each hand [kg] & 35 & 31,5 & 28 & 24,5 & 21 & 17,5 & 14 & 10,5 & 7 & 3,5 \\
\hline force on $L 4 / L 5[N]$ & 9283 & 8427 & 7708 & 6949 & 6069 & 5371 & 4588 & 3807 & 3023 & 2231 \\
\hline
\end{tabular}

Table 6: Positioning of a patient, nurse - man, percentile 50. [Authors]

\begin{tabular}{|c|c|c|c|c|c|c|c|c|c|c|}
\hline \multirow[t]{2}{*}{ The first case: Percentile 50} & \multicolumn{4}{|c|}{ Sex } & \multicolumn{3}{|c|}{ Weight [kg] } & \multicolumn{3}{|c|}{ Height [cm] } \\
\hline & & Male & & & 79 & & & 175 & & \\
\hline patient weight [\%] & 100 & 90 & 80 & 70 & 6 & 50 & 40 & 30 & 20 & 10 \\
\hline patient weight[kg] & 70 & 63 & 56 & 49 & 42 & 35 & 28 & 21 & 14 & 7 \\
\hline weight on each hand [kg] & 35 & 31,5 & 28 & 24,5 & 21 & 17,5 & 14 & 10,5 & 7 & 3,5 \\
\hline force on $L 4 / L 5[N]$ & 10905 & 10026 & 9146 & 8268 & 7388 & 6510 & 5630 & 4750 & 3871 & 2989 \\
\hline
\end{tabular}


Table 7: Positioning of a patient, nurse - man, percentile 99. [Authors]

\begin{tabular}{|c|c|c|c|c|c|c|c|c|c|c|}
\hline \multirow{2}{*}{ The first case: Percentile 99} & \multicolumn{4}{|c|}{ Sex } & \multicolumn{3}{|c|}{ Weight [kg] } & \multicolumn{3}{|c|}{ Height [cm] } \\
\hline & & Male & & & 108 & & & 191 & & \\
\hline patient weight [\%] & 100 & 90 & 80 & 70 & 6 & 50 & 40 & 30 & 20 & 10 \\
\hline patient weight [kg] & 70 & 63 & 56 & 49 & 42 & 35 & 28 & 21 & 14 & 7 \\
\hline weight on each hand [kg] & 35 & 31,5 & 28 & 24,5 & 21 & 17,5 & 14 & 10,5 & 7 & 3,5 \\
\hline force on $L 4 / L 5[N]$ & 12993 & 11993 & 10993 & 9996 & 9005 & 8007 & 7017 & 6022 & 5032 & 4038 \\
\hline
\end{tabular}

activities in TX Jack environment. Moreover, as NQ results reveal, the most heavily loaded body part is low, upper back and nape. This corresponds with the assumption of research regarding the regular patient handling. Modelling of typical working position of nurses when handling a patient and subsequent LBA analysis in the TX environment has helped us in evaluation quantification of back area loading. According to simulation, back loading could be simulated with changing percentage of manipulated patient weight, position on bed, nurse's position next to bed and his or her anthropometrics or population group. Tables 2. to Table 7. are designed with changing weight of a patient and manipulated weight converted to each hand of a nurse. Thanks to LBA analysis we can see how loading on intervertebral disc L4/L5 changes. Simulation results have confirmed the subjective evaluation result of nurses through NQ. Results presented in the article form basis for a prepared evaluation of nurses' work in inpatient departments, which could help us with modelling of nursing work activities thanks to use of TX simulation tool. It would help us in a way their loading in back area would be reduced and therefore health impacts resulting from a workload would be minimised.

The main part of the next research will be a proposal of the way of evaluation of physical stress in nurse work. Based on presented research will define the new method for evaluation of the physical load of nurse work. The proposed method should be validated in practice.

\section{Acknowledgments}

This paper is supported by KEGA project [022ZU-4/2018] entitled Elaboration of the innovative curricula of Ergonomics subject and Innovation Management subject for students of technical and scientific focus.

\section{References and Notes}

[1] Pedan, M., Gregor, M., Plinta, D.: Implementation of Automated Guided Vehicle System in Healthcare Facility. In: Procedia Engineering, vol. 192/2017, University of Zilina, Horny Smokovec, 2017.05.31, p-ISSN: 1877-7058, pp. 665-670.

[2] Krkoska, L., Gregor, M., Matuszek, J.: Simulation of human effect to the Adaptive Logistics System used in public facilities. Procedia Engineering, vol. 192, pp 492-497, 2017. ISSN: 1877-7058, doi: 10.1016/j.proeng.2017.06.085

[3] Národné centrum zdravotníckych informácií, Zdravotnícka ročenka Slovenskej republiky 2016, 2017. Online: < http:// www.nczisk.sk/Documents/rocenky/2016/Pracovnici_v_ zdravotnictve_a_zdravotnicke_skolstvo.pdf >

[4] Schall Jr., M.C., Fethke, B.N., Chen, H.: Working postures and physical activity among registered nurses. In: Applied Ergonomics. 2016. ISSN: 0003-6870. vol. 54, pp. 243-250.

[5] Nariadenie vlády Slovenskej republiky č. 281/2006 z 19. apríla 2006 o minimálnych bezpečnostných požiadavkách pri ručnej manipulácii s bremenami.

[6] Heiden, B., Weigl, M., Angerer, P., Muler, A.: Association of age and physical job demands with musculoskeletal disorders in nurses. In Applied Ergonomics. 2013. ISSN: 0003-6870.vol. 44, pp. 652-658.

[7] Wiitavaara, B., Barnekow-Bergkvist, M., Brulin, Ch.: Striving for balance: A grounded theory study of health experiences of nurses with musculoskeletal problems. 2007. In International Journal of Nursing Studies. Vol. 44, pp. 1379-1390.

[8] Plinta, D., Krajcovic, M.: Production systems designing with the use of digital factory and augmented reality technologies. In: Progress in automation, robotics and measuring techniques - control and automation. Eds. Roman Szewczyk, Cezary Zieliński, Małgorzata Kaliczyńska. Advances in Intelligent Systems and Computing, vol. 350, Cham, Heidelberg, Springer 2015, p-ISSN: 2194-5357, p-ISBN: 978-3-31915795-5, pp. 187-196

[9] Krajcovic, M., Plinta, D.: Comprehensive approach to the inventory control system improvement. In Management and Production Engineering Review. 2012. Vol. 3, Issue 3, ISSN 2082-1344, pp. 34-44.

[10] Zywicki, K., Zawadzki, P., Gorski, F.: Virtual reality production training system in the scope of intelligent factory. In: Intel- 
ligent System in Production Engineering and Maintenance - ISPEM 2017, Proceedings of the First International Conference on Intelligent Systems in Production Engineering and Maintenance ISPEM 2017, Springer International Publishing 2018, ISSN 2194-5357, ISBN 978-3-319-64464-6, pp. 450458.

[11] Bajana J., Francia, D., Liverani, A., Krajcovic, M.: Mobile tracking system and optical tracking integration for mobile mixed reality. In International journal of computer applications in technology. 2016. ISSN 0952-8091. Vol. 53, no. 1 (2016), pp. 13-22.

[12] Krehel, R., Kocisko, M., \& Poor, P. (2016). Technical Diagnostics in the Paper Industry. Proceedings Of The 27Th International DAAAM Symposium 2016, 0775-0784. doi: 10.2507/27th. daaam.proceedings.112

[13] Jasiulewicz-Kaczmarek, M. , Saniuk, A.: Human factor in sustainable manufacturing, Volume 9178, 2015, Pages 444455, 9th International Conference on Universal Access in Human-Computer Interaction, UAHCI 2015 Held as Part of 17th International Conference on Human-Computer Interaction, HCl International 2015; Los Angeles; United States; 2 August 2015 through 7 August 2015; Code 156679

[14] Pekarcikova, M., Trebuna, P., Kronova, J., Izarikova, G.: The application of software tecnomatix jack for design the ergonomics solutions. In: Intelligent Systems in Production Engineering and Maintenance. - Cham. Springer Nature Switzerland, pp. 325-336, 2019. ISBN 978-3-319-97490-3. ISSN 2194-5357, Online:https://www.scopus.com/record/ display.uri?eid=2-s2.0-85051769724\&origin=resultslist\&sort $=$ plf-f\&src $=$ s...

[15] Trebuna, P., Petrikova, A., Pekarcikova, M.: Influence of physical factors of working environment of workers performance from ergonomic point of view, In: Acta Simulation, vol. 3, no. 3., pp. 1-9, 2017, ISSN 1339-9640 Spôsob prístupu: http:// actasimulatio.eu/index.php?stranka=2017_03...

[16] Madzík, P., Chocholáková, A., Čarnogurský, K., Droppa, M., Lysá, L.: Is quality a philosophy or rather a mind-set? In: Quality - Access to Success. - ISSN 1582-2559, Vol. 18, Issue 161 (2017), p. 116-125.

[17] Straka, M., Khouri, S., Rosova, A., Caganova, D., Culkova, K. 2018. Utilization of computer simulation for waste separation design as a logistics system, International Journal of Simulation Modelling, Vol. 17, No. 4, pp. 583-596,

[18] Edl, M., Lerher, T., Rosi, B. 2013.: Energy efficiency model for the mini-load automated storage and retrieval systems. International Journal of Advanced Manufacturing Technology, , č. 2013, s. 1-19. ISSN: 0268-3768

[19] Straka, M., Malindzakova, M., Trebuna, P., Rosova, A., Pekarcikova, M., Fill, M. 2017: Application of EXTENDSIM for improvement of production logistics' efficiency. In: Interna- tional Journal of Simulation Modelling. Vol. 16, no. 3 (2017), p. 422-434. - ISSN 1726-4529

[20] Wicher, P., Staš, D., Karkula, M., Lenort, R., Besta, P.: A computer simulation-based analysis of supply chains resilience in industrial environment (Article), Metalurgija Volume 54, Issue 4, 2015

[21] www.ergonomicka.sk [04/2019] 